\title{
Desempenho de genótipos de milho cultivados com diferentes quantidades de palha de aveia-preta e doses de nitrogênio
}

\author{
Ademir de Oliveira Ferreira( ${ }^{(1)}$, João Carlos de Moraes Sá(2), Clever Briedis ${ }^{(1)}$ e André Gradowski de Figueiredo ${ }^{(3)}$ \\ (1)Universidade Estadual de Ponta Grossa (UEPG), Avenida Carlos Cavalcanti, no 4.748, CEP 84030-900 Ponta Grossa, PR \\ E-mail: aoferreira1@yahoo.com.br, cleverbriedis@yahoo.com.br (2)UEPG, Departamento de Solos e Engenharia Agrícola. \\ E-mail: jcmsa@uepg.br ${ }^{(3)}$ Monsanto do Brasil Ltda., Departamento de Tecnologia, Avenida das Nações Unidas, no 12901, Torre Norte, 7o andar, \\ Brokling Paulista, CEP 04578-910 São Paulo, SP. E-mail: andre.g.figueiredo@monsanto.com
}

\begin{abstract}
Resumo - O objetivo deste trabalho foi avaliar a resposta de genótipos de milho (Zea mays L.), cultivado em sistema de plantio direto, a diferentes quantidades de palha de aveia-preta (Avena strigosa Schreb.) e doses de nitrogênio. $\mathrm{O}$ experimento foi conduzido em um Latossolo Vermelho eutrófico, em delineamento experimental de blocos ao acaso em parcelas subsubdivididas, com três repetições. As parcelas principais foram representadas pelas quantidades de palha na superfície do solo (sem palha, 5,16 e 10,32 $\mathrm{Mg} \mathrm{ha}^{-1}$ ). As subparcelas foram representadas por três genótipos de milho e as subsubparcelas constituíram-se das doses $0,60,120,180$ e $240 \mathrm{~kg} \mathrm{ha}^{-1}$ de nitrogênio. $\mathrm{O}$ aumento da dose de nitrogênio reduziu a requeima das folhas e promoveu o suprimento adequado de nitrogênio das plantas de milho em todos os tratamentos com palha de aveia-preta. Os genótipos de milho diferenciaram-se quanto à produtividade de grãos, ao aproveitamento do nitrogênio mineralizado da palha e ao comprimento do sistema radicular, quando submetidos a diferentes quantidades de palha de aveia-preta e de nitrogênio.
\end{abstract}

Termos para indexação: Zea mays, deficiência nutricional, plantio direto, produção de grãos, sistema radicular.

\section{Corn genotype performance under black oat crop residues and nitrogen fertilization}

\begin{abstract}
The objective of this work was to assess the performance of corn (Zea mays L.) genotypes as affected by inputs of black oat (Avena strigosa Schreb.) residues applied on the soil surface and nitrogen fertilization under no-tillage system in a Typical Haplustox. The experiment was carried out in a complete randomized block design, arranged in split-split plots with three replicates. The main plots consisted of the amount of crop residues on the soil surface (no crop residue, 5.16 and $10.32 \mathrm{Mg} \mathrm{ha}^{-1}$ ). The split plots were three corn genotypes, and the split-split plots were five nitrogen rates: 0, 60, 120, 180, and $240 \mathrm{~kg} \mathrm{ha}^{-1}$. An increase in the nitrogen rates decreased nitrogen deficiency and provided an adequate nitrogen supply for corn, under all the amounts of black oat residues. The corn genotypes grown with different amounts of black oat residues and nitrogen rates had different grain yield responses, use of mineralized nitrogen from crop residues, and root growth.
\end{abstract}

Index terms: Zea mays, nutritional deficiency, no-tillage, grain yield, root system.

\section{Introdução}

O milho é o principal cereal produzido no Brasil, cultivado em cerca de 14,4 milhões de hectares, com produtividade média de $4 \mathrm{t} \mathrm{ha}^{-1}$ (IBGE, 2009). Um dos principais fatores responsáveis pela baixa produtividade é o manejo incorreto do adubo nitrogenado, cuja eficiência de utilização pela planta é influenciada pelo sistema de cultivo, tipo de fertilizante, formas de manejo e condições edafoclimáticas (Amado et al., 2002).
O nitrogênio $(\mathrm{N})$ é um componente fundamental na produtividade das culturas. Inúmeras pesquisas são realizadas para minimizar sua necessidade de aplicação, para reduzir sua perda por volatilização, lixiviação e desnitrificação e também para prolongar seu tempo de disponibilidade para as plantas. A adoção de sistemas conservacionistas de manejo do solo tem proporcionado alguns benefícios, tais como a elevação dos teores de $\mathrm{N}$ total nas camadas superficiais do solo (Purnomo et al., 2000) e a redução nas perdas por lixiviação. De acordo com Amado et al. $(1998,1999)$ e Sá et al. (2001), a 
redução da mobilização do solo causa efeito positivo no $\mathrm{N}$ total acumulado na camada mais superficial do solo nos sistemas conservacionistas, em relação ao sistema de plantio convencional (SPC). A redução de perdas por imobilização pelos microrganismos e a liberação gradual do nutriente são importantes para a redução de riscos ambientais.

$\mathrm{O}$ entendimento das transformações do $\mathrm{N}$ no solo é essencial para maximizar o seu uso pelas plantas e, por conseguinte, aumentar a eficiência do uso do fertilizante nitrogenado. $\mathrm{O} \mathrm{N}$ é o nutriente exigido em maior quantidade pelas culturas e, apesar de sua abundância na atmosfera, o solo é sua principal fonte para as plantas. A maior parte do $\mathrm{N}$ está ligada à matéria orgânica, componente essencial dos ecossistemas terrestres, cuja distribuição, conteúdo e qualidade têm um importante efeito nos processos que ocorrem no sistema (Sá et al., 2001).

Estudos têm sido realizados sobre o desenvolvimento radicular da cultura de milho afetado pela quantidade de resíduos culturais aportados e pelo tempo de adoção do plantio direto(Sá etal., 2007). Esses autores constataram que, quanto maior o tempo de adoção do sistema de plantio direto, melhor foi a distribuição e maior foi o desenvolvimento radicular do milho. Observaram também maior quantidade de raízes na camada de 0-10 cm no plantio direto $(19,3 \%)$ comparado ao preparo convencional (16,9\%). Verificaram ainda que os genótipos apresentaram comportamento diferenciado quanto ao desenvolvimento do sistema radicular, com a aplicação de doses adicionais de palha na superfície do solo, o que indicou que os genótipos apresentam características próprias sob sistema de plantio direto.

No Brasil, a introdução do sistema de plantio direto (SPD) e a sua expansão, como alternativa de manejo conservacionista do solo, têm gerado questionamentos no que se refere aos processos de transformação da matéria orgânica do solo (MOS), devido a alterações na dinâmica do carbono (C) e do N. O tempo de adoção do SPD, associado à rotação de culturas, é um componente essencial para o aumento do estoque de C (Bayer et al., 2000; Sá et al., 2001), principalmente quando comparado ao SPC. O revolvimento do solo põe os resíduos culturais em contato com os microrganismos, o que acelera a decomposição do material orgânico e a nitrificação do $\mathrm{N}$.

No SPD, as taxas de mineralização da MOS são reduzidas, quando comparadas às do $\mathrm{SPC}$, e resulta na liberação mais lenta e gradual do $\mathrm{N}$ na fase inicial de desenvolvimento das culturas. A maior exigência de $\mathrm{N}$, na fase inicial do SPD, está relacionada à ocorrência de picos de imobilização, e coincide com a demanda inicial de N pela planta (Amado et al., 1998; Vasconcellos et al., 1998; Sá, 1999). Todavia, a manutenção do SPD, associado ao aporte de resíduos culturais, promove a estabilização da MOS em um novo equilíbrio, em que menor taxa de decomposição da MOS é compensada pelo material orgânico adicionado (Bayer et al., 2000; Sá et al., 2001). Desta forma, a quantidade de fertilizante nitrogenado requerida é menor, considerando o mesmo nível de produtividade, e a maior eficiência de uso do fertilizante (Sá, 1999). Em contraste, quando os resíduos culturais são incorporados ao solo, ocorre rápida mineralização e liberação do $\mathrm{N}$, o que, muitas vezes, promove elevadas perdas do nutriente (Sá, 1993).

O objetivo deste trabalho foi avaliar a resposta de genótipos de milho em sistema de plantio direto a diferentes quantidades de palha de aveia-preta e doses de nitrogênio.

\section{Material e Métodos}

O experimento foi implantado na Fazenda Paiquerê, em Piraí do Sul, PR. A área experimental está situada a $24^{\circ} 32^{\prime} \mathrm{S}$ e $49^{\circ} 57^{\prime} \mathrm{W}$, e altitude de $974 \mathrm{~m}$. O clima é subtropical úmido, mesotérmico, do tipo cfb (Köppen). A temperatura média do mês mais quente é de $24^{\circ} \mathrm{C}$ e a do mês mais frio é de $15^{\circ} \mathrm{C}$. A pluviosidade total registrada entre abril de 2004 e março de 2005 foi de $1.763 \mathrm{~mm}$.

O solo é caracterizado como Latossolo Vermelho eutrófico típico (Santos et al., 2006). Os resultados das análises química e física do solo antes da implantação do experimento encontram-se na Tabela 1.

Tabela 1. Atributos químicos e físicos de um Latossolo Vermelho eutrófico sob sistema de plantio direto há 18 anos, antes da implantação do experimento.

\begin{tabular}{|c|c|c|c|c|c|c|c|c|c|c|c|c|}
\hline $\begin{array}{l}\text { Camada } \\
(\mathrm{cm})\end{array}$ & $\begin{array}{c}\mathrm{pH} \\
\mathrm{CaCl}_{2}\end{array}$ & $\begin{array}{c}\mathrm{C} \\
\left(\mathrm{g} \mathrm{dm}^{-3}\right)\end{array}$ & $\begin{array}{c}\text { P-Mehlich } 1 \\
\left(\mathrm{mg} \mathrm{dm}^{-3}\right)\end{array}$ & $\mathrm{Al}$ & $\mathrm{H}+\mathrm{Al}$ & $\begin{array}{c}\mathrm{Ca}+\mathrm{Mg} \\
\left(\mathrm{cmol}_{\mathrm{c}} \mathrm{dm}^{-3}\right. \\
\end{array}$ & $\mathrm{K}$ & CTC & $\begin{array}{c}\mathrm{V} \\
(\%) \\
\end{array}$ & Areia & $\begin{array}{r}\text { Silte } \\
\left(\mathrm{g} \mathrm{kg}^{-1}\right) \\
\end{array}$ & Argi \\
\hline $0-10$ & 5,1 & 32,0 & 32,3 & 0,0 & 6,69 & 9,5 & 0,57 & 16,7 & 60 & 129 & 251 & 620 \\
\hline $10-20$ & 5,2 & 38,0 & 4,5 & 0,0 & 7,20 & 9,2 & 0,34 & 16,7 & 57 & 152 & 168 & 680 \\
\hline
\end{tabular}


O delineamento experimental utilizado foi o de blocos ao acaso com arranjo em parcelas subsubdivididas, com três repetições. O tratamento principal foi constituído por três quantidades de palha (resíduos culturais de aveia-preta) na superfície do solo: 0, 5,16 e $10,32 \mathrm{Mg} \mathrm{ha}^{-1}$. A parcela com $5,16 \mathrm{Mg} \mathrm{ha}^{-1}$ equivale à quantidade de palha produzida na parcela, calculada pela média de dez pontos da avaliação realizada no momento da instalação do experimento. Toda a palha que estava na superfície do solo, após o corte das plantas rente ao solo, foi retirada para constituir o tratamento sem palha. Para evitar o revolvimento e manter a estrutura da camada superficial do solo, a palha foi retirada com o auxílio de rastelo com hastes de aço flexível. A parcela com 10,32 $\mathrm{Mg} \mathrm{ha}^{-1}$ foi obtida pela colocação da palha oriunda da parcela sem palha sobre a parcela com 5,16 $\mathrm{Mg} \mathrm{ha}^{-1}$. A subparcela foi constituída por três genótipos de milho com ciclos de desenvolvimento e maturidade fisiológica diferentes (AG 9020, AG 6018 e AG AG 8021). As subsubparcelas foram constituídas por cinco doses de nitrogênio $\left(0,60,120,180\right.$ e $\left.240 \mathrm{~kg} \mathrm{ha}^{-1}\right)$. Cada subparcela media $5,6 \times 30 \mathrm{~m}$ e cada subsubparcela media 5,6x6 m.

A área experimental encontrava-se há 18 anos sob SPD, com rotação das culturas: aveia-preta (Avena strigosa Schreb.)/soja (Glycine max Merr.) no inverno e verão do primeiro ano; trigo (Triticum aestivum L.)/ soja no segundo ano; e aveia-preta/milho (Zea mays L.) no terceiro ano. A cultura antecessora ao milho foi a aveia-preta para a formação de cobertura vegetal.

A semeadura do milho foi realizada no dia 27 de outubro de 2004, com auxílio de matracas, em sulcos abertos por semeadoras e espaçados de $0,8 \mathrm{~m}$ entre si. Foram colocadas duas sementes por cova para posterior desbaste. Na mesma data foi realizada a coleta do solo e da palha para análise.

Foram aplicados $225 \mathrm{~kg} \mathrm{ha}^{-1}$ do formulado $18-30-0$ (NPK) nas parcelas dos tratamentos com 60, 120, 180 e $240 \mathrm{~kg} \mathrm{ha}^{-1}$. Essa quantidade foi equivalente a $40,5 \mathrm{~kg} \mathrm{ha}^{-1}$ de $\mathrm{N}$ e $67,5 \mathrm{~kg} \mathrm{ha}^{-1}$ de $\mathrm{P}_{2} \mathrm{O}_{5}$. Nas parcelas do tratamento sem $\mathrm{N}$, a quantidade de $\mathrm{P}$ equivalente à dos tratamentos com $\mathrm{N}$ foi suprida pela aplicação de $147 \mathrm{~kg} \mathrm{ha}^{-1}$ de superfosfato triplo. O suprimento de potássio $(\mathrm{K})$ foi realizado antes da semeadura, em toda a área experimental, com distribuição a lanço de $100 \mathrm{~kg} \mathrm{ha}^{-1}$ de cloreto de potássio. O desbaste das plântulas de milho foi realizado 15 dias após a semeadura, para manter a população final de $65 \mathrm{mil}$ plantas por hectare. $\mathrm{O}$ restante das doses de $\mathrm{N}$ foi aplicado na forma de ureia, manualmente, a lanço, no estádio $\mathrm{V}_{6}$.

No estádio de florescimento pleno, foi realizada a avaliação do sistema radicular e a coleta de 30 folhasíndice por unidade experimental para a diagnose do estado nutricional. Também foi medida a altura das folhas requeimadas (cinco plantas por unidade experimental) com o sintoma de deficiência de $\mathrm{N}$ (V invertido). A produção de grãos foi determinada em 22 de março de 2005, nas duas linhas centrais de cada parcela, perfazendo $8 \mathrm{~m}$ lineares.

A quantificação do comprimento e da distribuição do sistema radicular no perfil do solo foi feita por processamento de imagens digitais, conforme descrito por Crestana et al. (1994). Em cada unidade experimental, foi escolhida uma planta para representar a parcela e feito uma trincheira para avaliação do sistema radicular. As trincheiras foram feitas no sentido perpendicular à linha central do milho, que estava no estádio de florescimento pleno. A face do perfil do solo para a avaliação das raízes foi centrada na linha da planta, e suas dimensões foram de $0,8 \mathrm{~m}$ de largura e $0,6 \mathrm{~m}$ de profundidade. Após feita a trincheira e realizada a escarificação manual do solo para exposição de 1 a $2 \mathrm{~cm}$ das raízes, aplicou-se na face exposta uma solução com 5\% de água sanitária comum, com um pulverizador costal com bico leque, para o clareamento das raízes. Posteriormente, foi adicionada uma cobertura com sombrite preto para manter as raízes hidratadas, deixando-se uma fina camada de solo umedecido para facilitar o processo de exposição do sistema radicular e o contraste com o solo. A escarificação do solo foi realizada com rastelo de hastes duras e retas, comumente chamado de "pente de crina de cavalo". $\mathrm{Na}$ face do perfil de solo escarificado foi colocado uma moldura com $0,8 \times 0,6 \mathrm{~m}$, para delimitar a área a ser avaliada. A moldura foi subdividida em 40 quadrículas $(0,1 \times 0,1 \mathrm{~m})$, com fios de náilon preto. As imagens das raízes de cada quadrícula foram obtidas com uma câmera digital com 3.2 megapixels. A quantificação do comprimento das raízes foi efetuada pelo programa Siarcs 3.0 (Crestana et al., 1994). Antes do uso do programa, as imagens foram processadas pelo programa Corel Draw versão 12.0, para obtenção de melhor contraste das imagens.

Os resultados foram submetidos à análise de variância pelo SISVAR 5.0, utilizando o teste de Tukey, a 5\% de 
probabilidade. Para a obtenção das curvas de resposta foi utilizado o procedimento da análise de regressão pelo programa JMP IN versão 3.2.1 (Sall et al., 2005), utilizando-se o teste $\mathrm{F}$, a 5,1 e $0,1 \%$ de probabilidade.

\section{Resultados e Discussão}

Houve interação significativa entre quantidade de palha $\mathrm{x}$ genótipo nas variáveis produtividade de grãos, $\mathrm{N}$ foliar e comprimento radicular. Também foram significativas as interações quantidade de palha $\mathrm{x}$ doses de $\mathrm{Ne}$ genótipo $\mathrm{x}$ doses de $\mathrm{N}$ nas variáveis produtividade de grãos, requeima e $\mathrm{N}$ foliar (Tabela 2).

Nas quantidades de palha de 0 e $5,16 \mathrm{Mg} \mathrm{ha}^{-1}$, as maiores produtividades de grãos foram obtidas pelos genótipos AG 9020 e AG 8021 (Tabela 3). Já para quantidade de $10,32 \mathrm{Mg}^{-1} \mathrm{a}^{-1}$ não houve diferença entre os genótipos. A maior produtividade de grãos do genótipo AG 6018 ocorreu nas quantidades de palha de 5,16 e 10,32 $\mathrm{Mg} \mathrm{ha}^{-1}$. Isso reforça o conceito de que os genótipos têm comportamento diferenciado em relação à quantidade de palha na superfície do solo produzida pela cultura antecessora. Sá et al. (2007) observaram ampla faixa de resposta de genótipos dentro de cada quantidade de palha. Essa faixa de resposta parece estar associada ao ciclo do genótipo e à resposta ao $\mathrm{N}$, uma vez que a adição de palha com elevada relação $\mathrm{C} / \mathrm{N}$ provoca competição de $\mathrm{N}$ entre a planta de milho e os microrganismos do solo (Sá et al., 2007).

O genótipo AG 8021 apresentou maior teor de $\mathrm{N}$ na folha em relação ao genótipo AG 9020, nos tratamentos com 5,16 e $10,32 \mathrm{Mg} \mathrm{ha}^{-1}$ de palha. Isso se explica por esse genótipo possuir ciclo mais longo que o AG 9020, o que permitiu ao genótipo AG 8021 maior aproveitamento do $\mathrm{N}$ mineralizado da palha (Figura $1 \mathrm{~B}$, Tabela 3). Consequentemente a altura da requeima das folhas foi menor (Figura $1 \mathrm{C}$ ).

$\mathrm{O}$ incremento da quantidade de palha na superfície do solo provocou aumento na altura de requeima das folhas pela deficiência de $\mathrm{N}$ (Figura $2 \mathrm{C}$ ). Isso se explica pela imobilização do $\mathrm{N}$ mineral do solo $\left(\mathrm{NH}_{4}{ }^{+}\right.$ e $\mathrm{NO}_{3}^{-}$) pelos microrganismos, para decomposição do resíduo vegetal, na época de demanda de $\mathrm{N}$ pela planta (Sá, 1996).

A altura da requeima reduziu drasticamente quando a dose de $\mathrm{N}$ foi aumentada, o que indica uma compensação de $\mathrm{N}$ para a absorção da planta pelo fornecimento do fertilizante nitrogenado. $\mathrm{O}$ tratamento testemunha foi $\mathrm{o}$ que apresentou maior altura de requeima (Figura $1 \mathrm{C}$ ) e, consequentemente, os sintomas de deficiência de $\mathrm{N}$.

$\mathrm{O}$ aumento das doses de $\mathrm{N}$ teve reflexo direto na produtividade de grãos (Figura $2 \mathrm{~A}$ ) e no teor de $\mathrm{N}$ na folha-índice (Figura $2 \mathrm{~B}$ ) e na altura da requeima das folhas. Ocorreu melhor distribuição do $\mathrm{N}$ e maior transferência para os grãos, o que garantiu maior produtividade (Fancelli \& Dourado Neto, 2000). Resultados semelhantes foram obtidos por Gomes et al. (2007) no Município de Rio Verde (GO), onde os autores constataram aumento do rendimento de grãos e do teor de $\mathrm{N}$ nas folhas com o incremento das doses de N.

Em todos os tratamentos o teor de $\mathrm{N}$ nas folhas (Tabela 3) foi inferior aos descritos como adequados (27,5 a 32,5 $\left.\mathrm{g} \mathrm{kg}^{-1}\right)$ por Malavolta et al. (1997). Resultados semelhantes foram obtidos por Silva et al. (2005), que atribuíram tal fato às características do híbrido utilizado, aliado ao uso do SPD, pois nesse

Tabela 2. Análise de variância da produtividade de grãos $\left(\mathrm{kg} \mathrm{ha}^{-1}\right)$, altura de requeima $(\mathrm{cm})$, nitrogênio foliar $\left(\mathrm{g} \mathrm{kg}^{-1}\right)$ e comprimento radicular $\left(\mathrm{m} \mathrm{m}^{-2}\right)$, em razão da quantidade de palha, do genótipo e das doses de nitrogênio, em um Latossolo Vermelho eutrófico, após 18 anos de plantio direto.

\begin{tabular}{|c|c|c|c|c|}
\hline Causas da variação & Produtividade & Requeima & $\mathrm{N}$ foliar & Raiz \\
\hline Quantidade de palha & ns & ns & ns & ns \\
\hline CV $(\%)$ & 15,36 & 139,95 & 16,25 & 22,22 \\
\hline Genótipo & * & * & $*$ & * \\
\hline Quantidade de palha x genótipo & $*$ & ns & $*$ & $*$ \\
\hline CV $(\%)$ & 13,98 & 139,81 & 15,98 & 22,54 \\
\hline Doses de $\mathrm{N}$ & * & * & $*$ & ns \\
\hline Quantidade de palha $\mathrm{x}$ doses de N & $*$ & * & $*$ & ns \\
\hline Genótipo $\mathrm{x}$ doses de $\mathrm{N}$ & $*$ & * & $*$ & ns \\
\hline Quantidade de palha $\mathrm{x}$ genótipo $\mathrm{x}$ doses de $\mathrm{N}$ & ns & ns & ns & ns \\
\hline CV $(\%)$ & 12,88 & 86,62 & 11,65 & 24,9 \\
\hline
\end{tabular}

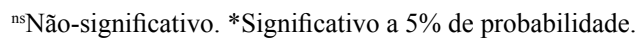


sistema ocorre menor variação de temperatura e umidade no solo. A faixa adequada de $\mathrm{N}$ nas folhas do milho em SPD pode ser inferior à adequada para o milho cultivado no sistema de preparo convencional do solo. Muzilli (1983), ao estudar o efeito de preparos do solo e de rotação de culturas, também constatou menores teores de $\mathrm{N}$ foliar no SPD.

A elevada produção de grãos obtida pelos genótipos (Figura $2 \mathrm{~A}$ ) foi coerente com a fertilidade do solo (Tabela 1). A média do tratamento sem $\mathrm{N}$ foi de $8.365 \mathrm{~kg} \mathrm{ha}^{-1}$ (Tabela 3). Conforme Sá (1999), solos com elevado conteúdo de matéria orgânica, acumulada devido ao longo período de adoção do plantio direto, possuem elevado potencial de produção.

A aplicação de 60 e $120 \mathrm{~kg} \mathrm{ha}^{-1}$ de $\mathrm{N}$ atingiu, respectivamente, 91,7 e $98,6 \%$ da produtividade máxima do experimento $\left(10.553 \mathrm{~kg} \mathrm{ha}^{-1}\right)$. Dados semelhantes foram obtidos por Sá (1996) na região dos Campos Gerais (Paraná), em que o autor relata que dose superiores a $120 \mathrm{~kg} \mathrm{ha}^{-1}$ de $\mathrm{N}$ não têm resultado em aumento da produtividade de grãos. Tem-se observado redução da necessidade de aplicação de $\mathrm{N}$ ao longo do tempo de adoção do plantio direto. Em várias situações de campo têm sido obtidas produtividades de 8.500 a $9.000 \mathrm{~kg} \mathrm{ha}^{-1}$ de grãos com o fornecimento de $60 \mathrm{a}$ $120 \mathrm{~kg} \mathrm{ha}^{-1}$ de N (Sá, 1996, 1999; Bodey et al., 1997). Na mesma região, Pauletti \& Costa (2000) reportou produtividade de até $9.000 \mathrm{~kg} \mathrm{ha}^{-1}$ do milho cultivado

Tabela 3. Produtividade de milho $\left(\mathrm{kg} \mathrm{ha}^{-1}\right)$, altura de requeima $(\mathrm{cm})$, nitrogênio foliar $\left(\mathrm{g} \mathrm{kg}^{-1}\right)$ e comprimento radicular $\left(\mathrm{m} \mathrm{m}^{-2}\right)$, em razão da interação quantidade de palha $\mathrm{x}$ genótipo, em um Latossolo Vermelho eutrófico, após 18 anos de plantio direto ${ }^{(1)}$.

\begin{tabular}{|c|c|c|c|}
\hline \multirow[t]{2}{*}{ Genótipos } & \multicolumn{3}{|c|}{ Quantidade de palha $\left(\mathrm{Mg} \mathrm{ha}^{-1}\right)$} \\
\hline & 0 & 5,16 & 10,32 \\
\hline & \multicolumn{3}{|c|}{ Produtividade de grãos $\left(\mathrm{kg} \mathrm{ha}^{-1}\right)$} \\
\hline AG 9020 & $10.195 \mathrm{Aa}$ & $10.446 \mathrm{Aa}$ & $10.042 \mathrm{Aa}$ \\
\hline AG 6018 & $8.177 \mathrm{Bb}$ & $9.176 \mathrm{Ab}$ & $9.378 \mathrm{Aa}$ \\
\hline \multirow[t]{2}{*}{ AG 8021} & $10.102 \mathrm{Aa}$ & $10.171 \mathrm{Aa}$ & 9.904Aa \\
\hline & \multicolumn{3}{|c|}{ Nitrogênio na folha-índice $\left(\mathrm{g} \mathrm{kg}^{-1}\right)$} \\
\hline AG 9020 & $24,0 \mathrm{Aa}$ & $22,8 \mathrm{Ab}$ & $22,7 \mathrm{Ab}$ \\
\hline AG 6018 & $24,6 \mathrm{Aa}$ & $24,3 \mathrm{Aab}$ & $23,5 \mathrm{Ab}$ \\
\hline \multirow{2}{*}{ AG 8021} & $25,6 \mathrm{Aa}$ & $25,9 \mathrm{Aa}$ & $25,1 \mathrm{Aa}$ \\
\hline & \multicolumn{3}{|c|}{ Comprimento radicular $\left(\mathrm{m} \mathrm{m}^{-2}\right)$} \\
\hline AG 9020 & $19,5 \mathrm{Ab}$ & $21,2 \mathrm{Aa}$ & $20,1 \mathrm{Aab}$ \\
\hline AG 6018 & $18,8 \mathrm{Ab}$ & $20,1 \mathrm{Aa}$ & $18,0 \mathrm{Ab}$ \\
\hline AG 8021 & $22,8 \mathrm{Aa}$ & $19,2 \mathrm{Ba}$ & $21,6 \mathrm{Aa}$ \\
\hline
\end{tabular}

${ }^{(1)}$ Médias seguidas por letras iguais, minúsculas nas colunas e maiúsculas nas linhas, não diferem entre si pelo teste de Tukey, a $5 \%$ de probabilidade.
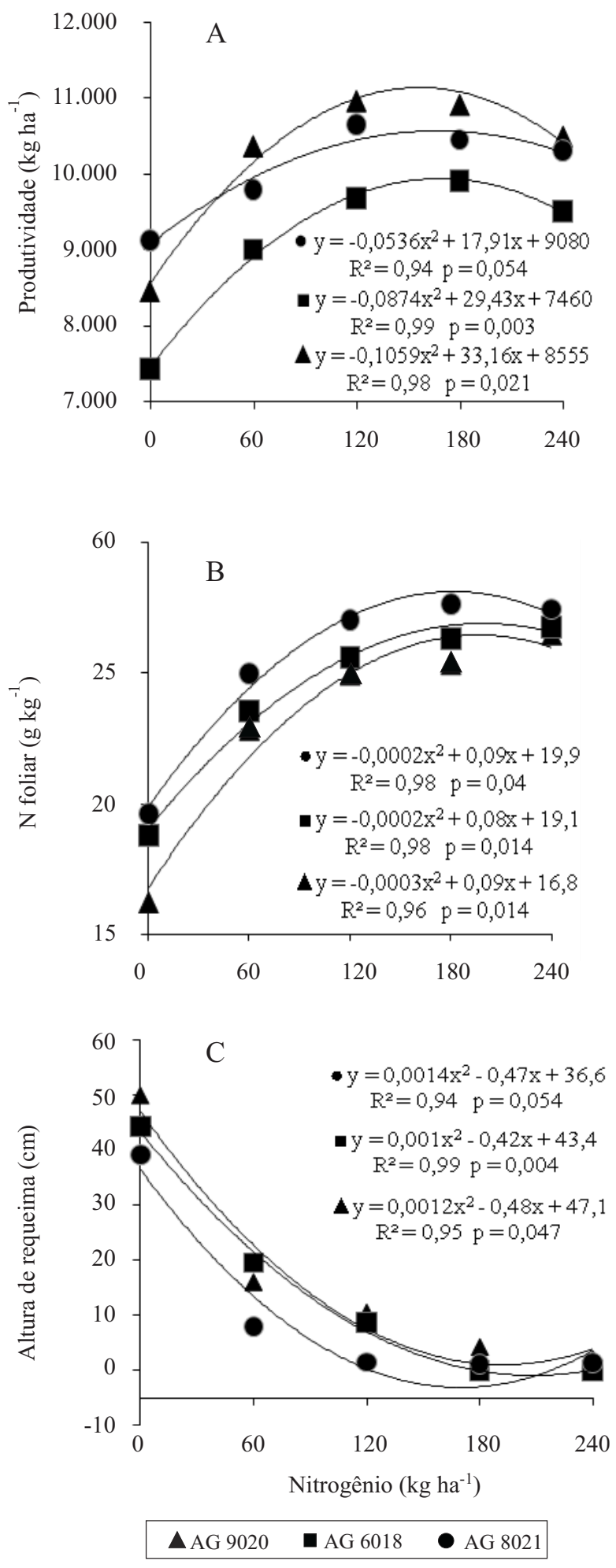

Figura 1. Produtividade de grãos, nitrogênio foliar e altura de requeima, em razão da interação genótipo $\mathrm{x}$ doses de nitrogênio, em um Latossolo Vermelho eutrófico, após 18 anos de plantio direto. 

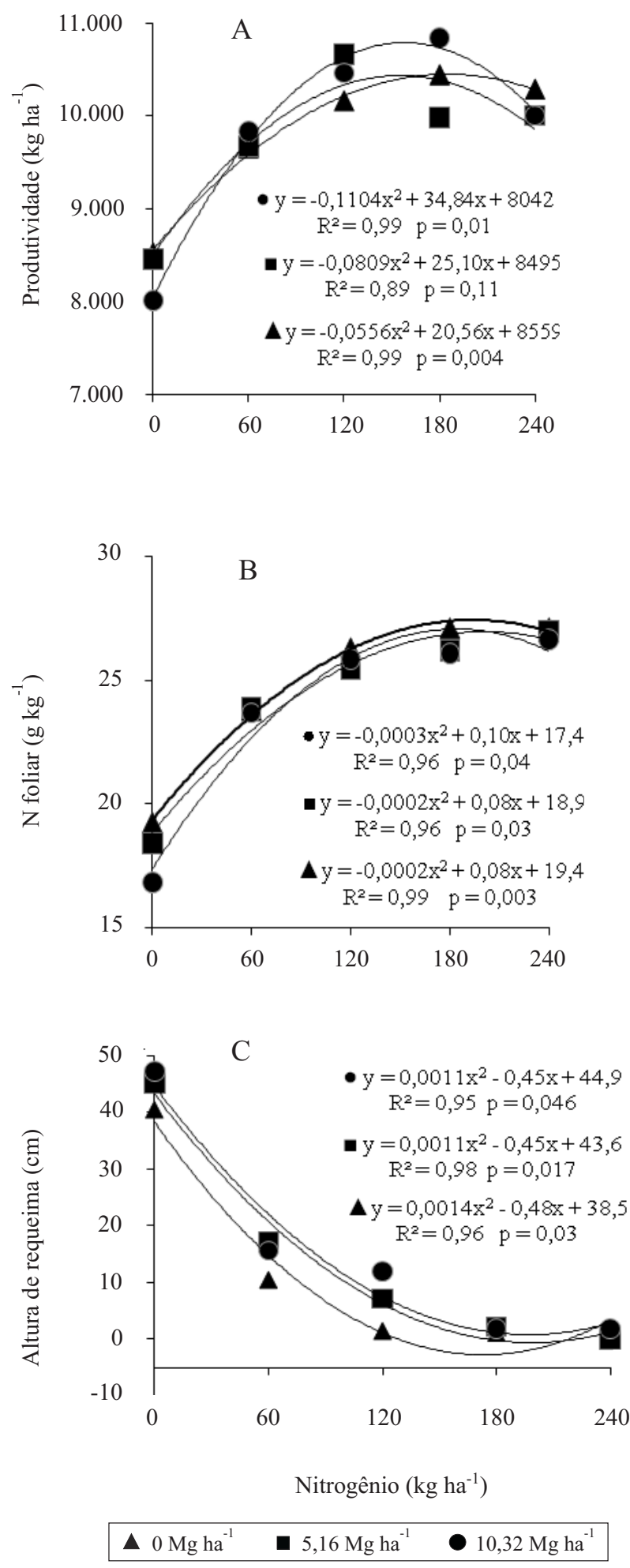

Figura 2. Produtividade de grãos, nitrogênio foliar e altura de requeima, em razão da interação quantidade de palha $\mathrm{x}$ doses de nitrogênio, em um Latossolo Vermelho eutrófico, após 18 anos de plantio direto. após aveia-preta, sem aplicação de N. O tempo de adoção do plantio direto e a rotação de culturas são os fatores preponderante para se alcançar esses resultados. Nesses solos o teor do $\mathrm{N}$ total é superior a 7,5 $\mathrm{Mg} \mathrm{ha}^{-1}$ (Sá et al., 2001), o que proporciona elevada disponibilidade de $\mathrm{N}$ para a planta.

\section{Conclusões}

1. Os genótipos de milho apresentam comportamento diferenciado em relação à produtividade de grãos, aproveitamento do nitrogênio mineralizado da palha e comprimento radicular, quando submetidos a diferentes quantidades de palha de aveia-preta na superfície do solo e a diferentes doses de nitrogênio, em sistema de plantio direto consolidado.

2. O aumento da dose de nitrogênio, independentemente da quantidade de palha de aveia-preta aplicada na superfície do solo, reduz a requeima das folhas e promove o suprimento adequado de nitrogênio para as plantas de milho.

\section{Agradecimentos}

À Monsanto do Brasil Ltda, pelo suporte financeiro; à Universidade Estadual de Ponta Grossa e à Agropecuária Lúcio Miranda, pelo auxílio na condução do experimento, coleta e análise de amostras.

\section{Referências}

AMADO, T.J.C.; FERNANDEZ, S.B.; MIELNICZUK, J. Nitrogen availability as affected by ten years of cover crop and tillage systems in southern Brazil. Journal of Soil and Water Conservation, v.53, p.268-271, 1998.

AMADO, T.J.C.; MIELNICZUK, J.; AITA, C. Recomendação de adubação nitrogenada para o milho no RS e SC adaptada ao uso de culturas de cobertura do solo, sob sistema de plantio direto. Revista Brasileira de Ciência do Solo, v.26, p.241-248, 2002.

AMADO, T.J.C.; MIELNICZUK, J.; FERNANDES, S.B.V.; BAYER, C. Culturas de cobertura, acúmulo de nitrogênio total no solo e produtividade do milho. Revista Brasileira de Ciência do Solo, v.23, p.679-686, 1999.

BAYER, C.; MIELNICZUK, J.; AMADO, T.J.C.; MARTIN-NETO, L.; FERNANDES, S.V. Organic matter storage in a sandy clay loam Acrisol affected by tillage and cropping systems in southern Brazil. Soil and Tillage Research, v.54, p.101-109, 2000.

BODDEY, R.M.; SÁ, J.C. de M.; ALVES, B.J.R.; URQUIAGA, S.S. The contribution of biological nitrogen fixation for sustainable agricultural systems in the tropics. Soil Biology and Biochemistry, v.29, p.787-799, 1997. 
CRESTANA, S.; GUIMARÃES, M.F.; JORGE, L.A.C.; RALISCH, R.; TOZZI, C.L.; TORRE, A.; VAZ, C.M.P. Avaliação da distribuição de raízes no solo auxiliada por processamento de imagens digitais. Revista Brasileira de Ciência do Solo, v.18, p.365-371, 1994.

FANCELli, A.L.; DOURADO NETO, D. Produção de milho. Guaíba: Agropecuária, 2000. 360p.

GOMES, R.F.; SILVA, A.G. da; ASSIS, R.L. de; PIRES, F.R. Efeito de doses e da época de aplicação de nitrogênio nos caracteres agronômicos da cultura do milho sob plantio direto. Revista Brasileira de Ciência do Solo, v.31, p.931-938, 2007.

IBGE. Levantamento sistemático da produção agrícola: janeiro/2009. Disponível em: <http:// www.ibge.gov.br>. Acesso em: 28 jan. 2009.

MALAVOLTA, E.; VITTI, G.C.; OLIVEIRA, S.A. de. Avaliação do estado nutricional das plantas: princípios e aplicações. 2.ed. Piracicaba: Potafos, 1997. 319p.

MUZILLI, O. Influência do sistema plantio direto, comparado ao convencional, sobre a fertilidade da camada arável do solo. Revista Brasileira de Ciência do Solo, v.7, p.95-102, 1983.

PAULETTI, V.; COSTA, L.C. Época de aplicação de nitrogênio no milho cultivado em sucessão à aveia-preta no sistema plantio direto. Ciência Rural, v.30, p.599-603, 2000.

PURNOMO, E.; BLACK, A.S.; SMITH, C.J.; CONYERS, M.K. The distribution of net nitrogen mineralisation within surface soil. 1. Field studies under a wheat crop. Australian Journal of Soil Research, v.38, p.129-140, 2000.

SÁ, J.C. de M. Manejo da fertilidade do solo no plantio direto. Castro: Fundação ABC, 1993. 96p.

SÁ, J.C. de M. Manejo da fertilidade do solo no sistema plantio direto. In: SIQUEIRA, J.O.; MOREIRA, F.M.S.; LOPES, A.S.; GUILHERME, L.R.G.; FAQUIM, V.; FURTINI NETO, A.E.; CARVALHO, J.G. (Ed.). Inter-relação fertilidade, biologia do solo e nutrição de plantas. Lavras: SBCS, 1999. p.267-319.

SÁ, J.C. de M. Manejo do nitrogênio na cultura do milho no sistema plantio direto. Passo Fundo: Aldeia Norte, 1996. 24p.

SÁ, J.C. de M.; CERRI, C.C.; DICK, W.A.; LAL, R.; VENSKE FILHO, S.P.; PICCOLO, M.C.; FEIGL, B.E. Organic matter dynamics and carbon sequestration rates for a tillage chronosequence in a Brazilian Oxisol. Soil Science Society of America Journal, v.65, p.1486-1499, 2001.

SÁ, J.C. de M.; SANTOS, J.B.; CARDOSO, E.G.; SIUTA JÚNIOR, D.; FERREIRA, C.F.; FERREIRA, A.O.; MASSINHAM, A.; SÁ, M.F.M. Manejo de fertilizantes nitrogenados em sistemas de produção envolvendo os cultivos de soja/trigo e soja/milho safrinha no sistema plantio direto. In: YAMADA, T.; ABDALLA, S.R.S. e; VITTI, G.C. (Ed.). Nitrogênio e enxofre na agricultura brasileira. Piracicaba: International Plant Nutrition Institute, 2007. v.1, p.567-649.

SALL, J.; CREIGHTON, L.; LEHMAN, A. JMP start statistics: a guide to statistics and data analysis using JMP and JMP IN software. $3^{\text {rd }}$ ed. Cary: Duxbury Press, 2005. 580p.

SANTOS, H.G. dos; JACOMINE, P.K.T.; ANJOS, L.H.C. dos; OLIVEIRA, V.A. de; OLIVEIRA, J.B. de; COELHO, M.R.; LUMBRERAS, J.F.; CUNHA, T.J.F. (Ed.). Sistema brasileiro de classificação de solos. 2.ed. Rio de Janeiro: Embrapa Solos, 2006. $306 \mathrm{p}$.

SILVA, E.C. da; BUZETTI, S.; GUIMARÃES, G.L.; LAZARINI, E.; SÁ, M.E. de. Doses e épocas de aplicação de nitrogênio na cultura do milho em plantio direto sobre Latossolo Vermelho. Revista Brasileira de Ciência do Solo, v.29, p.353-362, 2005.

VASCONCELLOS, C.A.; FIGUEIREDO, A.P.H.D.; FRANÇA, G.E. de; COELHO, A.M.; BRESSAN, W. Manejo do solo e a atividade microbiana em Latossolo Vermelho-Escuro da região de Sete Lagoas, MG. Pesquisa Agropecuária Brasileira, v.33, p.1897-1905, 1998.

Recebido em 10 de abril de 2008 e aprovado em 30 de janeiro de 2009 